\title{
On the non-generic Tzitzeica-Johnson's Configuration
}

\section{Wladimir G. Boskoff, Şerban Bărcănescu and Alexandru Bobe}

\begin{abstract}
Working in the context of Hilbert's axiomatic system, we prove that the Tzitzeica-Johnson configuration has sense in neutral geometry. The elements of a Tzitzeica-Johnson configuration allow us to analyse the Euclidean or the non-Euclidean character of the metric of the plane.
\end{abstract}

\section{Introduction}

The statement of the analogue of Tzitzeica-Johnson theorem in the neutral geometry is described by the following theorem as it appears in [2].

Theorem 1. Let $H, O_{1}, O_{2}, O_{3}$ four points in the neutral plane such that $\left|O_{1} H\right|=$ $=\left|O_{2} H\right|=\left|O_{3} H\right|$ and $H \in \operatorname{Int}\left(\Delta O_{1} O_{2} O_{3}\right)$. Consider

$$
A=S_{O_{1} O_{2}} H, \quad B=S_{O_{3} O_{1}} H, \quad C=S_{O_{2} O_{3}} H .
$$

Then there exists a point $O$ in the neutral plane such that $|O A|=|O B|=|O C|$.

Therefore in the case when $\mathrm{H} \in \operatorname{Int}\left(\Delta \mathrm{O}_{1} \mathrm{O}_{2} \mathrm{O}_{3}\right)$, called the generic case, it exists a Tzitzeica-Johnson configuration in the neutral plane and it was denoted by $\left[\mathrm{H}, \mathrm{O}_{1} \mathrm{O}_{2} \mathrm{O}_{3} \mid \mathrm{O}, \mathrm{ABC}\right]$ (see [2]).

In the Euclidean plane, the generic Tzitzeica-Johnson's configuration has the property that $[\mathrm{OA}],[\mathrm{OB}],[\mathrm{OC}],\left[\mathrm{HO}_{1}\right],\left[\mathrm{HO}_{2}\right],\left[\mathrm{HO}_{3}\right]$ all are congruent segments.

Key Words: Neutral plane, axiom of parallels, Tzitzeica problem, Johnson problem.

2010 Mathematics Subject Classification: 51F05, 51M05, 51M09, 51M10.

Received: August, 2011.

Accepted: February, 2012. 
In the neutral plane we have that $[O A],[O B],[O C]$ are congruent and separately that $\left[\mathrm{HO}_{1}\right],\left[\mathrm{HO}_{2}\right],\left[\mathrm{HO}_{3}\right]$ are congruent.

It is natural to compare $[O A]$ and $\left[H O_{1}\right]$ in order to establish certain properties of the neutral plane itself.

To formulate the next result we use the comparison of the angles and of the segments as introduced in [10]. By the notation $\mathrm{R}$ we mean the right angle in the plane. By the sign $\Re$ we mean any of the relations $>,=,<$.

The result which allows to highlight the importance of a generic TzitzeicaJohnson's configuration in the neutral plane in establishing the type of the metric is the following (see [2]).

Theorem 2. Let $\left[\mathrm{H}, \mathrm{O}_{1} \mathrm{O}_{2} \mathrm{O}_{3} \mid \mathrm{O}, \mathrm{ABC}\right]$ be a generic Tzitzeica-Johnson's configuration in the neutral plane. Let $\Sigma$ be the sum of the angles of $\triangle \mathrm{O}_{1} \mathrm{O}_{2} \mathrm{O}_{3}$. If $[A O] \Re\left[H O_{1}\right]$ then $\Sigma \Re 2 R$.

At this point we introduce a new definition. We call non-generic TzitzeicaJohnson configuration, the geometric figure in the neutral plane such that the point $\mathrm{H}$ doesn't lie in the interior of $\Delta \mathrm{O}_{1} \mathrm{O}_{2} \mathrm{O}_{3}$. Our goal becomes to obtain an equivalent theorem in the case of non-generic Tzitzeica-Johnson's configuration. We have to analyze two possibilities.

\section{Undecidability in the case $H \in \partial\left(\Delta O_{1} O_{2} O_{3}\right)$}

Suppose now that $\mathrm{H}$ lies on the boundary of $\Delta \mathrm{O}_{1} \mathrm{O}_{2} \mathrm{O}_{3}$. Denote this case by $\left[\mathrm{H}, \partial\left(\mathrm{O}_{1} \mathrm{O}_{2} \mathrm{O}_{3}\right) \mid \mathrm{O}, \mathrm{ABC}\right]$

Without loss of generality (see Figure 1 ) we can assume that $H$ lies on the segment $\left[O_{1} O_{3}\right]$, such that $\left|H O_{1}\right|=\left|H O_{2}\right|=\left|H O_{3}\right|$. Then

$$
S_{O_{1} O_{3}} H=H=B, \quad S_{O_{1} O_{2}} H=A \quad S_{O_{2} O_{3}} H=C .
$$

Denote $\{T\}=A H \cap O_{1} O_{2}$ and $\{K\}=C H \cap O_{2} O_{3}$. Remark that $\triangle A T O_{2} \equiv$ $\triangle H T O_{2}$, which yields $\left|O_{2} A\right|=\left|O_{2} H\right|\left(=\left|O_{2} B\right|\right)$. Similarly from $\triangle C K O_{2} \equiv$ $\triangle \mathrm{HKO}_{2}$ we get $\left|\mathrm{CO}_{2}\right|=\left|\mathrm{O}_{2} \mathrm{H}\right|\left(=\left|\mathrm{O}_{2} \mathrm{~B}\right|\right)$. Therefore $\mathrm{O}_{2}$ is equidistant from $A, B=H$, and $C$.

This shows that when $H$ lies on the boundary, the Tzitzeica-Johnson configuration has the same structure in both Euclidean and non-Euclidean cases. In fact, in this case, one can not decide if the geometry is Euclidean or hyperbolic. 


\section{The case when $\mathrm{H}$ lies in the exterior of $\Delta \mathrm{O}_{1} \mathrm{O}_{2} \mathrm{O}_{3}$ : Anal- ysis}

Now we analyze the Tzitzeica-Johnson configuration when $H$ lies in the exterior of $\Delta \mathrm{O}_{1} \mathrm{O}_{2} \mathrm{O}_{3}$. For this discussion we refer to Figure 2.

Suppose that $\left[\mathrm{HO}_{1}\right.$ is between $\left[\mathrm{HO}_{2}\right.$ and $\left[\mathrm{HO}_{3}\right.$ as in Figure 4. Let $\mathrm{A}=$ $S_{O_{1} O_{2}} H, B=S_{O_{1} O_{3}} H$, and $C=S_{O_{2} O_{3}} H$. The rays $[H A,[H B$ and $[H C$ bisect $\angle \mathrm{O}_{2} \mathrm{HO}_{1}, \angle \mathrm{O}_{1} \mathrm{HO}_{3}$, and $\angle \mathrm{O}_{2} \mathrm{HO}_{3}$, respectively. Consider now the perpendicular bisectors of $[A B]$ and $[A C]$. One of them is perpendicular on $[A B]$, the other one is slant. In the Hilbert axiomatic sistem corresponding to Euclidean geometry is easy to see that these perpendicular bisectors meet. On the other hand, in the axiomatic framework corresponding to neutral geometry there is no criterion to decide if the two lines intersect.

So, in the case of a non-generic Tzitzeica-Johnson configuration if there is not $O$ such that $|O A|=|O B|=|O C|$ it results that our geometry is hyperbolic. Let us denote such configuration by $\left[\mathrm{H}, \operatorname{ext}\left(\mathrm{O}_{1} \mathrm{O}_{2} \mathrm{O}_{3}\right) \mid \nexists O, A B C\right]$.

Let us analyze the Tzitzeica-Johnson configuration in the case when the perpendicular bisectors of $[A B]$ and $[A C]$ meet in a point $O$ in neutral geometry. Let us denote this case by $\left[\mathrm{H}\right.$, ext $\left.\left(\mathrm{O}_{1} \mathrm{O}_{2} \mathrm{O}_{3}\right) \mid \mathrm{O}, \mathrm{ABC}\right]$. First, let us describe the construction of these perpendicular bisectors. Let $L$ be the midpoint of $[A B]$. Then $O_{1} L$ is perpendicular on $A B$ since $\triangle O_{1} L B$ and $\triangle O_{1} L A$ are congruent (case SSS). Similarly, denote by $D$ the midpoint of $[A C]$. In the same way, $\mathrm{O}_{2} D \perp A C$ by the same congruence case in $\triangle \mathrm{O}_{2} D A \equiv \triangle \mathrm{O}_{2} D C$. Thus, the perpendicular bisector of $[A B]$ and $[A C]$ are $O_{1} L$ and $O_{2} D$, respectively. By our assumption, let $O$ be their point of intersection. Then the perpendicular bisector of $[B C]$ passes also through $O$. The construction of the perpendicular bisector of $[B C]$ is similar: the midpoint $Y$ of $[B C]$ determines the line $\mathrm{O}_{3} Y$ which is the perpendicular bisector of $[B C]$. Furthermore, $O \in\left[\mathrm{O}_{3} Y\right.$. At this point, let us focus on $\Delta \mathrm{O}_{2} \mathrm{O}_{3} \mathrm{O}$. We denote by $x$ the equal angles

$$
\angle \mathrm{HO}_{1} \mathrm{O}_{2}=\angle \mathrm{HO}_{2} \mathrm{O}_{1}=\angle A O_{1} \mathrm{O}_{2}=\angle A O_{2} \mathrm{O}_{1} .
$$

Then remark that $\angle \mathrm{OO}_{2} \mathrm{O}_{3}$ has also measure $x$, since $\left[\mathrm{O}_{2} \mathrm{O}_{3}\right.$ bisects $\angle \mathrm{HO}_{2} \mathrm{C}$ and $\left[\mathrm{O}_{2} \mathrm{O}\right.$ bisects $\angle \mathrm{CO}_{2} \mathrm{~A}$. By analogy, denoting by $y$ the measure of equal angles $\angle \mathrm{HO}_{1} \mathrm{O}_{3}=\angle \mathrm{HO}_{3} \mathrm{O}_{1}=\angle \mathrm{BO}_{1} \mathrm{O}_{3}=\angle \mathrm{BO}_{3} \mathrm{O}_{1}$, we obtain that $\angle \mathrm{O}_{2} \mathrm{O}_{3} \mathrm{O}$ has measure $y$. For $\angle \mathrm{O}_{2} \mathrm{OO}_{3}$, the reasoning is different. Denote by $z$ the measure of $\angle A O_{1} O=\angle B O_{1} O$, and by $u$ the measure of $\angle A O O_{1}=\angle B O O_{1}$. The reasoning made to measure $\angle \mathrm{O}_{2} \mathrm{OO}_{3}$ still holds true due to the fact that $\left[\mathrm{OO}_{2}\right.$ bisects $\angle \mathrm{COA}$ and $\left[\mathrm{OO}_{3}\right.$ bisects $\mathrm{COB}$. Thus $\angle \mathrm{O}_{2} O \mathrm{O}_{3}$ has measure $u$. The sum of the angles around $O_{1}$ yields $2 x+2 y+2 z=4 R$ (we use the standard notation with $R$ for the measure of a right angle), thus $x+y+z=2 R$. The sum of angles in $\Delta \mathrm{O}_{2} \mathrm{OO}_{3}$ is $x+y+u$. 
Denote by $\Re$ one of the symbols $>,=,<$. Denote by $\Sigma$ the sum of the angles of the triangle $\mathrm{O}_{2} \mathrm{OO}_{3}$.

Theorem 3. In the case of the non-generic Tzitzeica-Johnson configuration $\left[\mathrm{H}, \operatorname{ext}\left(\mathrm{O}_{1} \mathrm{O}_{2} \mathrm{O}_{3}\right) \mid O, A B C\right]$ we have $\left|O_{1} H\right| \Re|O A|$ if and only if $\Sigma \Re 2 R$.

Proof: In order to complete the proof let us observe that $u \Re z$ if and only if $\left|O_{1} H\right| \Re|O A|$, that is if and only if $\Sigma \Re 2 R$. $\square$

One more comment can be made. Since the sum of the angles of a triangle in Hilbert's neutral plane is less than or equal $2 R$ (Legendre's theorem) we obtain both in the case of a generic configuration and in the case of a nongeneric configuration that the metric can be Euclidean of Hyperbolic only. Except the case when $H \in \partial\left(\Delta O_{1} O_{2} O_{3}\right)$, one can decide the type of the metric knowing the type of the configuration and looking at the comparison between the segments $\left|O_{1} H\right|$ and $|O A|$. All these are syntetised in the following.

Theorem 4. (Main Theorem) Consider a Tzitzeica-Johnson configuration.

a) $\left[H, O_{1} O_{2} O_{3} \mid O, A B C\right]:|A O| \Re\left|H O_{1}\right| \Longleftrightarrow \Sigma \Re 2 R$, where $\Sigma$ is the sum of angles of the triangle $\mathrm{O}_{1} \mathrm{O}_{2} \mathrm{O}_{3}$; the metric can be Euclidean or hyperbolic.

b) $\left[\mathrm{H}, \partial\left(\mathrm{O}_{1} \mathrm{O}_{2} \mathrm{O}_{3}\right) \mid O, A B C\right]$ : the metric can not be decided between Euclidean and hyperbolic.

c) $\left[H\right.$, ext $\left.\left(O_{1} O_{2} O_{3}\right) \mid \nexists O, A B C\right]$ : the metric is hyperbolic.

d) $\left[H, \operatorname{ext}\left(\mathrm{O}_{1} \mathrm{O}_{2} \mathrm{O}_{3}\right) \mid O, A B C\right]:\left|O_{1} H\right| \Re|O A| \Longleftrightarrow \Sigma \Re 2 R$, where $\Sigma$ is the sum of angles of the triangle $\mathrm{O}_{2} \mathrm{OO}_{3}$; the metric can be Euclidean or hyperbolic.

This complets the study of the Tzitzeica-Johnson configuration according to Barbilian's point of view.

\section{References}

[1] D. Barbilian - Pagini inedite, volume 2, Editors G. Barbilian and V. G. Vodă, Editura Albatros, 1984.

[2] W. Boskoff, S. Barcanescu - On the Tzitzeica-Johnson configuration, Journal of Geometry, 96(2009), 57-61.

[3] W. Boskoff and P. Horja - The characterization of some special Barbilian spaces using the Tzitzeica construction, Stud. Cerc. Mat. 46 (1994), No. $5,503-514$.

[4] A. Emch - Remarks on the foregoing circle theorem, American Mathematical Monthly, 23(1916), 162-164.

[5] M. J. Greenberg - Aristotle's axiom in the foundations of geometry J. Geom. 33(1988), 53-57. 
[6] M. J. Greenberg - Euclidean and Non-Euclidean geometries, Development and history, Third edition, W. H. Freeman \& Co., 1993.

[7] R. Hartshorne - Non-Euclidean III.36 Amer. Math. Monthly 110(2003), 495-502.

[8] D. Hilbert - The Foundations of Geometry, Open Court Publishing Company, La Salle, 1962 (reprint of the translation by E. J. Townsend, 1902).

[9] R. A. Johnson - A Circle Theorem, Amer. Math. Monthly, 23(1916), 161-162.

[10] B. Kerekjarto Les fondements de la geometrie, vol. 1, Akad. Kiado, Budapest, 1955.

[11] T. Lalescu - Geometry of the Triangle (in Romanian: Geometria triunghiului), Ed. Apollo, 1993 (original French edition in 1937).

[12] N. N. Mihăileanu - Complementary Lessons in Geometry, (in Romanian: Lecţii complementare de geometrie), Editura didactică şi pedagogică, Bucureşti, 1976.

[13] N. N. Mihăileanu et al. - A Problem Book of Synthetic and Projective Geometry (in Romanian: Culegere de probleme de geometrie sintetică şi proiectivă), Editura didactică şi pedagogică, 1971.

[14] V. Pambuccian - Zum Stufenaufbau des Parallelenaxioms J. Geom. 51(1994), 79-88.

[15] V. Pambuccian - Constructive axiomatizations of plane absolute, Euclidean and hyperbolic geometry Math. Log. Q. 47(2001), 129-135.

[16] G. Pólya - Mathematical discovery. On understanding, learning, and teaching problem solving, Reprint in one volume. With a foreword by Peter Hilton. With a bibliography by Gerald Alexanderson. With an index by Jean Pedersen. John Wiley \& Sons, Inc., New York, 1981, xxv+220 pp.

[17] G. Tzitzeica On a Euler's Theorem(romanian), Gazeta Matematică, 13(1907), 293-294.

[18] G. Tiţeica - Problems of Geometry (in Romanian: Probleme de geometrie, Sixth Edition, with foreword by Gh. D. Simionescu, Editura Tehnică, 1962, reprinted 1981. 
[19] V. Gh. Vodă - The Charm of Old-Fashioned Geometry (in Romanian: Vraja geometriei demodate), Editura Albatros, 1983.

Wladimir G. BOSKOFF,

Department of Mathematics,

Ovidius University of Constanta,

Bdul Mamaia 124, 900527 Constanta, Romania.

Email: boskoff@univ-ovidius.ro

Şerban BĂRCĂNESCU,

Institute of Mathematics of the Romanian Academy,

Calea Grivitei 21, Bucharest, Romania.

Email: serban.barcanescu@imar.ro

Alexandru BOBE,

Department of Mathematics,

Ovidius University of Constanta,

Bdul Mamaia 124, 900527 Constanta, Romania.

Email: alexb@univ-ovidius.ro 